\title{
Failure Stress Energy Formula
}

\section{Zviad Kovziridze}

Institute of Bionanoceramics and Nanocomposites Technology, Georgian Technical University, Tbilisi, Georgia

Email: kowsiri@gtu.ge

How to cite this paper: Kovziridze, $\mathrm{Z}$. (2018) Failure Stress Energy Formula. Journal of Electronics Cooling and Thermal Control, 8, 31-47.

https://doi.org/10.4236/jectc.2018.83003

Received: September 1, 2018

Accepted: September 25, 2018

Published: September 28, 2018

Copyright $\odot 2018$ by author and Scientific Research Publishing Inc. This work is licensed under the Creative Commons Attribution International License (CC BY 4.0).

http://creativecommons.org/licenses/by/4.0/

\begin{abstract}
Goal: In the process of exploitation of ceramic composites often we encounter not only high mechanical stresses but also thermal loads and air-thermal shocks. These loads are transformed into failure/rupture stress energy, when strength of work-pieces is less than loads, which develops pluck from the crack top, resulting in destruction of objects. Considering such extreme operation conditions computation of energies which contribute to materials catastrophe seems rather interesting. Method: The formula parameters were selected on the basis of study and generalization of micro- and macro-mechanical characteristics of ceramic materials. Results: The formula covers the process of creation of energies as a result of mechanical and thermal loads affecting the work-piece and analyses of mechanisms of impact of these energies on the cracks existing in the material; results of energies affecting the existing cracks as a result of such loads and results of starting of mechanisms of spreading of energies developed inside the work piece, which lead material to the catastrophe. Conclusion: On the basis of crack development mechanisms the universal relationship of total energy of the work-piece and its mass was established considering crack developing speed under critical stress conditions. Failure stress energy formula has been offered.
\end{abstract}

\section{Keywords}

Crack Development Speed, Failure/Destruction Stress, Mechanical and Thermal Loads, Mass

\section{Introduction}

Material strength implies maximum resistance to external and inner tensions. Distances between atoms in the crystalline lattice and interaction forces between atoms determine theoretical strength of materials. Strength of aluminum oxide destruction at bending, according to the power of bonds between atoms, approximately equals to $50,000 \mathrm{MPa}$, while majority of technical versions of 
strength shows 300 - $350 \mathrm{MPa}$ and materials characterized by extremely high hardness show $1000 \mathrm{MPa}[1]$.

Such great discrepancy between theoretical and practical strengths is conditioned by the fact that ceramic materials reveal extreme sensitivity to non-homogeneities and structure defects, such as: inclusions, pores, macro- and micro-cracks. It should be stated that even in case of high technologies it is a very hard problem to avoid such structural flaws. At the morphological study of materials a significant role is attributed to crystalline phase, which is the component that intensifies most the structure. Rearrangement of crystalline phase in the lattice and its sizes exert significant impact on mechanical properties. Fine dispersion dimensions below $5 \mathrm{mcm}$ and their homogeneous spreading increase mechanics of any type ceramic, while their big sizes such as $20-40 \mathrm{mcm}$ and higher and unequal spreading in the material mass, decrease not only mechanical but also exploitation properties such as resistance to thermal and air-thermal shocks, electro- and magnetic properties, durability and exploitation at heavy stress conditions, e.g. on power transmission lines, reduction of stress threshold values and others [2] [3] [4]. Vitreous phase compared to the crystalline phase is the weak component of a lattice, but if crystals and pores are homogeneously arranged in it, it acts as connecting and compacting component for these phases. Of course in this case small content of vitreous phase will play a relatively positive role, e.g. at the sintering of solid phases, when volumetric share of vitreous phase is less than $12 \%$.

Similarly, porous phase exerts complex impact on various properties of ceramics. Great significance is attributed to dimension of pores, their volumetric share, form, closed and round form, through or semi-through form.

The more fine-dispersion are pores which are homogeneously spread in the lattice, the stronger is the material; material is durable and resistant to thermal, air-thermal shock, mechanical stress and shocks. Pores markedly affect complex properties of work-pieces. Their rounded forms, small size pores, less than 5 $\mathrm{mcm}$ and their equal arrangement increase resistance of ceramics to external loads. When open porosity according to water absorption equals to zero, volumetric share of closed pores in the lattice varies within $0.5-9$ vol. \%. As to the invisible micro cracks, according to Griffiths they exist in any thermally treated material [5] [6]. At the terms of mechanical load, thus for example, in water turbines or air-turbines and in flying apparatuses in the process of starting, stress intensities are maximal. At this moment, stress intensities are evident at the crack top and in the critical case the cracks, and especially big size cracks are developed via detachment. At this moment, cracks can be developed by $2000 \mathrm{~m} / \mathrm{sec}$ speed [7] and it can result immediate catastrophe. In this case critical coefficient of stress intensity-Kic plays the significant rope, which is connected with critical intensity of release of elastic energy, or with decomposition viscosity Gic. At the volumetric stress condition $\mathrm{K}^{2} \mathrm{ic}=\mathrm{E} \mathrm{Gic}\left(1-\mu^{2}\right)$, where $-\mu$, is a Poisson coefficient. Stress intensity coefficient (SIC) is a value, which determines normal 
stress at the $\sigma_{y}$ point, which is located in short distance from $\mathrm{r}$-crack top and expresses local stresses near the crack.

Under the load a body with a crack reaches marginal state of equilibrium, when the crack starts movement or it can move from the place at the slight increase of the given load. In this case stress intensity coefficient will be limiting, critical for this material at the given load conditions. In the elastic body with a crack, if axis is perpendicular to the fault direction, SIC in asymptotic approximation will be expressed by $\mathrm{K}=\lim \sqrt{2 \pi r \sigma y}$ where Kic is a value, that characterizes viscous decomposition of material [7]. Material properties, especially at mechanical loads are determined mainly according to the forms of atom bonds and their inter-distribution in solid body [8].

\section{The Main Part}

At the impact of forces of interaction between atoms the crystalline structures are created with strictly ordered distances between atoms. In equilibrium state sum of repulsion and attraction between two neighbor atoms equals to zero (Figure 1).

Displacement of atoms from balanced state becomes possible only at the impact of external forces. Figure 1 shows schematically the sum of $\mathrm{F}$ forces acting between two atoms, as the function of a distance " $a$ " from each other. In equilibrium condition atoms will acquire $a_{0}$ inter-space characteristic for such atoms. In case of displacement by $\Delta a$ distance, effect of counteraction/resistance is formed that corresponds to the forces for attraction-repulsion. If displacement is small, ratio of the resistance forces and distance between atoms is linear. After removal of load the balanced state is restored, deformation is reversible that is

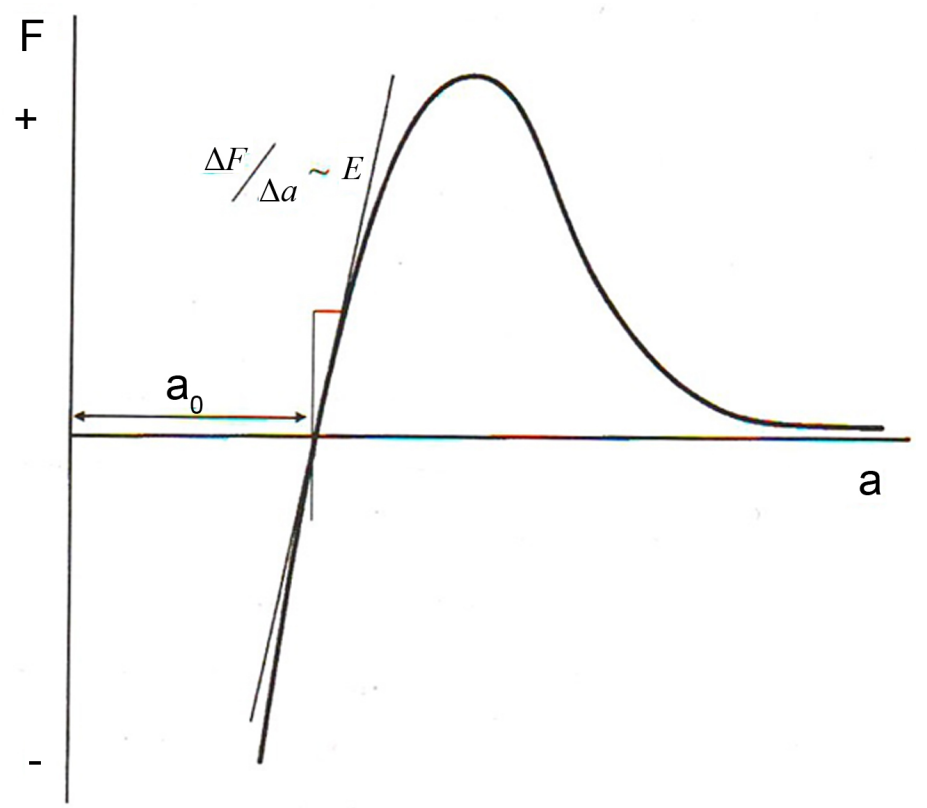

Figure 1. $F$-force (attraction + , repulsion -; balanced space $a_{0}$ ) that resulted between two neighbor atoms in solid body, at a distance $a$. 
recoverable, relaxed. Thus, most types of materials are linearly elastic till definite limits [9].

For consideration of excess stress and stress displacement around the pore the elliptic form of the pore in the plate (Figure 2) serves as the vivid phenomenon. Elliptic dimensions are defined by the main axes $b$ and $a$. Radius of curvature at the external $S$ elliptic point reaches $\rho=b^{2} / a$. At this spot stress $\sigma_{s}$ in the direction of the loaded force $\sigma$ are aches maximum:

$$
\sigma S / \sigma a=1+2(a / \rho)^{1 / 2}
$$

According to the above given equation, in case of circular pore at the excess of stress we receive factor 3 . Stresses will be higher when curvature radius at elliptic edge is sharp. In case of marginal stress in the ellipsis a crack with the curvature radius $\rho=0$ will be created. Stresses in this case will be infinitely large. In reality, such mathematical case can't be encountered since minimal curvature radius equals to the distance between the atoms. In reality immediately at the crack top extremely high stresses are formed, which are close to the theoretical hardness [10].

\subsection{Stress Intensity Factor}

Crack curvature radius $\rho$ at the crack top is very small and because of it $(a / \rho)^{1 / 2}$ will be rather high. Thus in the Equation (1) the summand 1 may become insignificant. Excess of pressure at the crack top is approximately proportional of external pressure $\sigma_{a}$ (distant field of compression) on the crack-containing material as well as of a root from crack length $a$. This law leads us to determination of the stress intensity coefficient $\mathrm{Ki}$, as tension measure at the crack top section.

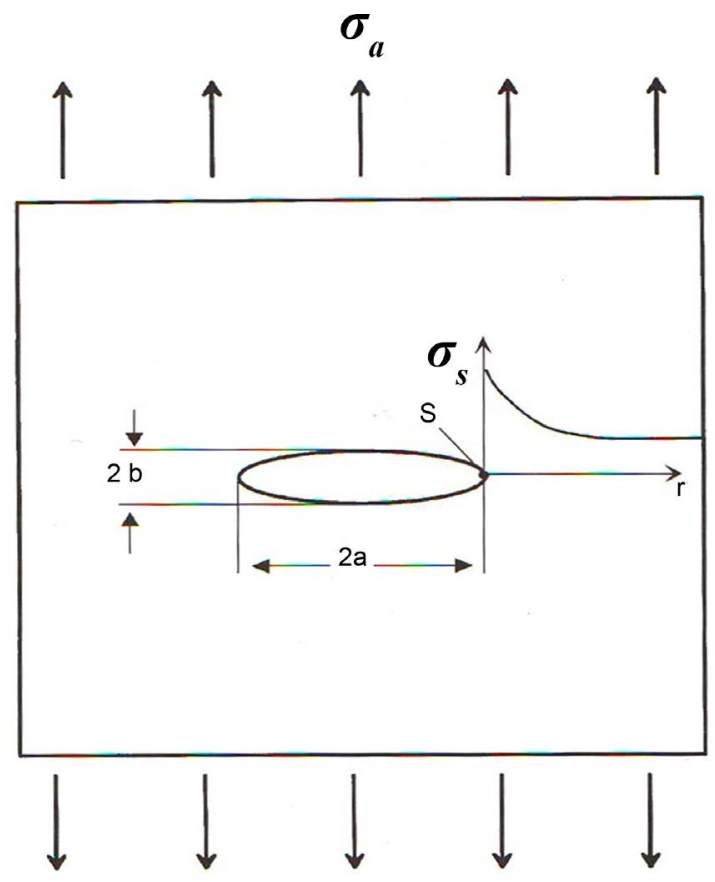

Figure 2. Excess stress $\sigma_{s}$ around elliptic pore, in model plate. 


$$
\mathrm{Ki}=\sigma \sqrt{a \mathrm{Y}}
$$

Geometrical factor $\Upsilon$ considers geometrical dimensions of crack-containing work-pieces and stress distribution in it. This factor is computed by means of numerical method according to various type loads and it is given in standard tables. Stress intensity factor index shows crack load regime, where the most risky section for material decomposition is loading state that is expressed by modus 1. In distinct from it, load at the crack sides is given by modus II, while load as a result of twisting-is given by modus III. II and III modi in special cases are of technical significance (e.g. composite materials or coatings). In case of monolith materials practically only modus I is used [11].

Stress spreading near the crack top is given by polar coordinates (Figure 3), where $r$-is distance from the crack top, and $\varphi$ is the angle.

\subsection{Crack Propagation at the Terms of Critical Loading}

Cracks start to grow slowly when stress intensity factor acquires critical value, that is, when the crack tolerance in the process of loading and resistance energy are minimal and when even minimal increase of any load will turn into decomposition energy. Such process of loading results in increase of crack sizes. This phenomenon is called preceding critical period of crack increase [11]. To describe this process we consider crack increase speed, as Ki function of stress intensity factor. Many materials act so, as we see on the typical v-Ki curve (Figure 4). Crack increase at the $\mathrm{Ki}_{\mathrm{th}}$ threshold value is not registered. At the increase of loading, initially we observe slow acceleration of crack increase (mostly at $10^{-12}$ $\mathrm{m} / \mathrm{sec}$ ), which alongside with the increase of the stress intensity factor in the first section it is increased within the frames of ratio regularities [10].

$$
\mathrm{V}=\mathrm{AK} 1 \mathrm{n}=\mathrm{A} *\left(\frac{\mathrm{K}_{\mathrm{i}}}{\mathrm{K}_{\mathrm{ic}}}\right)
$$

where $\mathrm{K}_{\mathrm{IC}}$ is coefficient of stress intensity factor. Parameters A (respectively $\mathrm{A}^{\star}$ ) and $\mathrm{n}$ depend on the material, temperature and environment. Correspondingly,

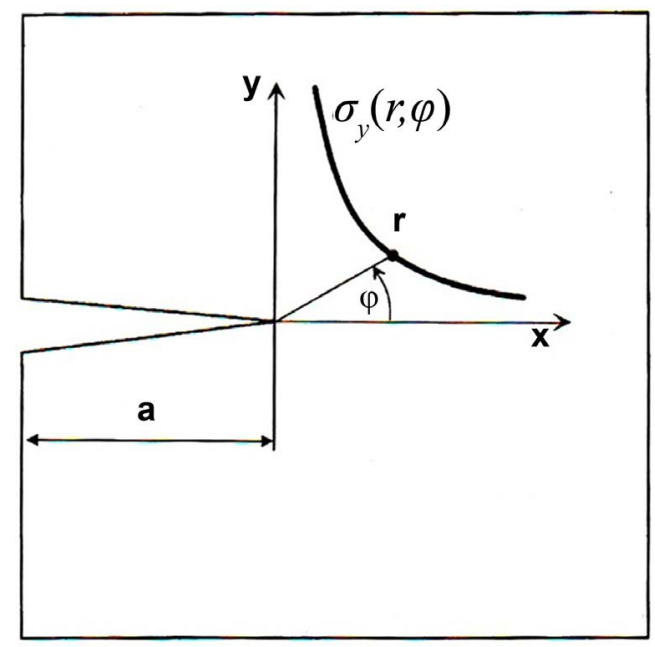

Figure 3. Stress distribution at the crack top section. 


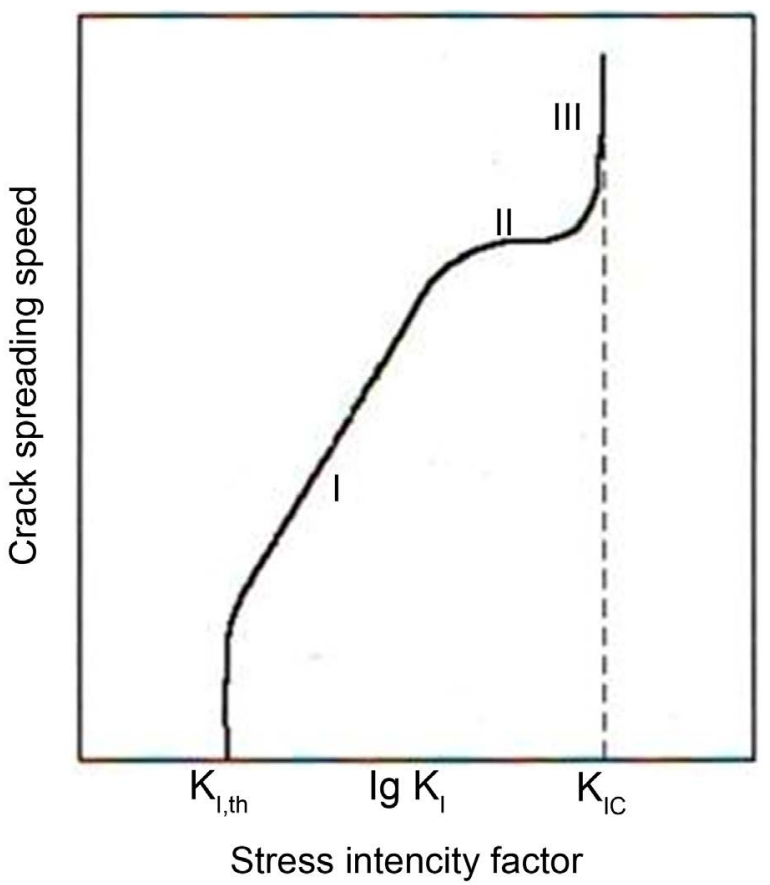

Figure 4. Typical graph of crack spreading speed according to stress intensity factor, when pre-critical state of crack increase (v-K-curve) develops. On the horizontal - stress intensity factor; on the vertical—crack increase speed.

for crack propagation speed at the 1 section, we consider environment diffusion at the crack top and the available stress. For most ceramics the exponent $\mathrm{n}>15$. For some materials section II is acceptable, when crack spreading speed stops growing. Crack speed is so high, that increase of the stress intensity factor does no more affect crack speeding, and the diffusion, as the process that determines acceleration (that runs very slowly) slows down.

When stress intensity factor overcomes crack resistance (section III), the stress disintegration energy develops and rapid growth of the crack occurs by its detachment and the process practically reaches the top speed. It is namely in this moment that crack spreading speed develops that equals to approximately 2000 $\mathrm{m} / \mathrm{sec}$ (Figure 4, section III). When we deal with the stress permanently (thus e.g. on power transmission lines, on electro-technical devices or at the operation processes) and the crack slowly increases, the stress intensity factor will always grow. In this case crack increase in material life period is always permanent. When at the late stage the section II is achieved the life-duration somewhat decreases, and technically it loses significance for relevant evaluation of life duration.

\subsection{Criteria Evaluation of Resistance to Thermal and Air-Thermal Shocks in the Process of Stress Distribution in Materials}

Materials, which operate in transitional/critical temperature fields and under high mechanical loads, are characterized by thermal stresses and deformations in the conditions, when their mechanical and chemical properties don't suffer sig- 
nificant changes. The problem is complicated since as a rule, alongside with thermal stresses mechanical stresses are acting from external loads, which contribute to development of high energies in materials. In this case developed energies exert marked impact on cracks and where there is a weak section in the lattice and there are cracks there, their development occurs via detachment plucking. In such cases catastrophic destruction of material is inevitable [12]. Thermal stresses can be formed mostly: at the restricted thermal expansion of a body, at equal spreading of temperature in polycrystalline body with anisotropic crystals, or in isotropic body which up to loading was fixed by limiting forces, at temperature gradients in the body, by cyclic changes of body temperature, when it is mechanically well fixed, by single non-standard thermal heating [13] [14] [15] [16]. At long-term operation conditions almost complete relaxation of thermal stresses takes place; therefore at gradual changes of temperature danger of destruction is caused mainly by mechanical loads. Thermal cyclic stresses (thermal fatigue and drastic changes in temperature-thermal shock) are the main causes or factors for material destruction. Thus, testing in strict conditions provides relatively wide sphere of exploitation of work-pieces. It is necessary to take into consideration inner stresses, according to their locality [17].

1) Zero order stress is formed in the system of reciprocally connected bodies, due to unequal thermal impact on those bodies or because of different linear temperature expansion coefficients.

2) First order (microscopic) stresses, which are balanced in the spheres of body sizes, are conditioned by non-homogeneity of temperature fields or by body properties.

3) Second order (microscopic) stresses can be formed in case of absence of the first order stresses and they have independent values.

4) Third order defects (sub-microscopic) can't be called stresses, since stresses are measured in the least zones spheres and they are insignificant. Such defects are revealed in the distances between atoms and their study is difficult.

Identification of faults in separate grains or at their borders and then complete destruction of the material is conditioned by accumulation of defects, which are formed at the effect of thermo-structural stresses as a result of multiple cycles of high temperature impacts or during high mechanical stresses (Figure 5)

Dynamic micro-hardness and elasticity module of the obtained Si-Al-O-N material were determined on the modern dynamic micro-hardness tester "rome DUH-211S" according to the demands of ISO-14577 International standards, used for determination of mechanical characteristics of solid body surfaces (micro-hardness, elasticity module). Results are offered in Table 1 [18] [19].

Phase composition (\%) of Si-Al-O-N composite according to the morphological pattern is: $\mathrm{Si}-\mathrm{Al}-\mathrm{O}-\mathrm{N}-62.6$; silicon carbide -28.0 ; aluminum oxide -6.2 ; porous phase -3.2. Composite was obtained at the first stage by metal-thermal and nitriding processes at $1450^{\circ} \mathrm{C}$. Then the composite was dispensed in Teflon mill and was hot-compressed at $1620^{\circ} \mathrm{C}$. 


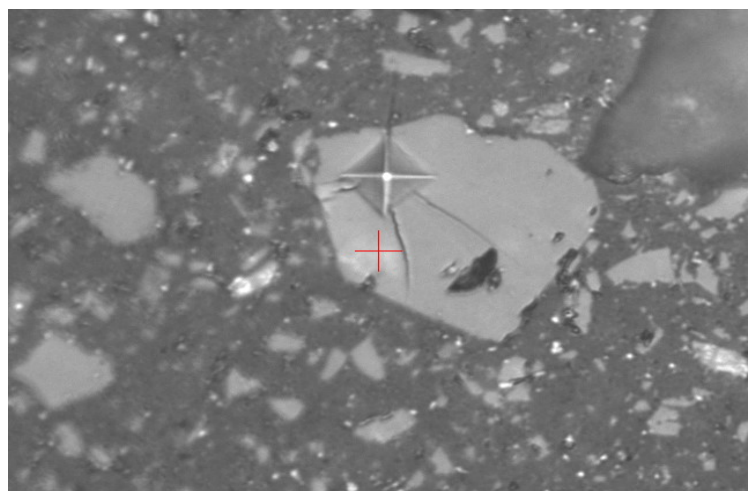

(a)

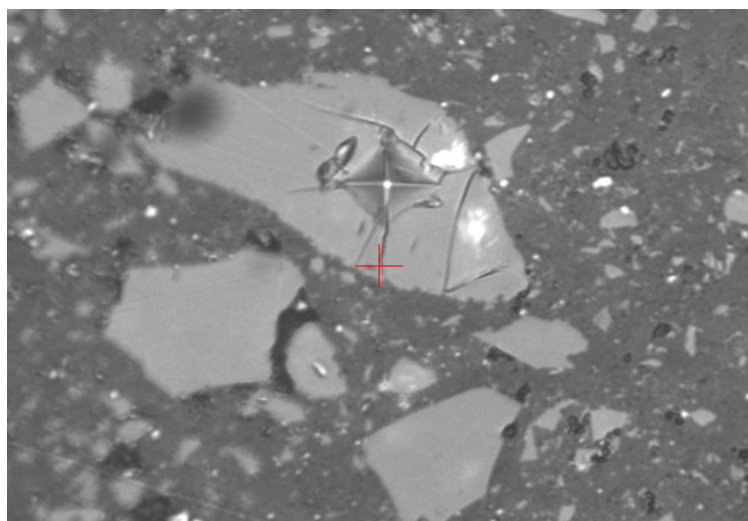

(b)

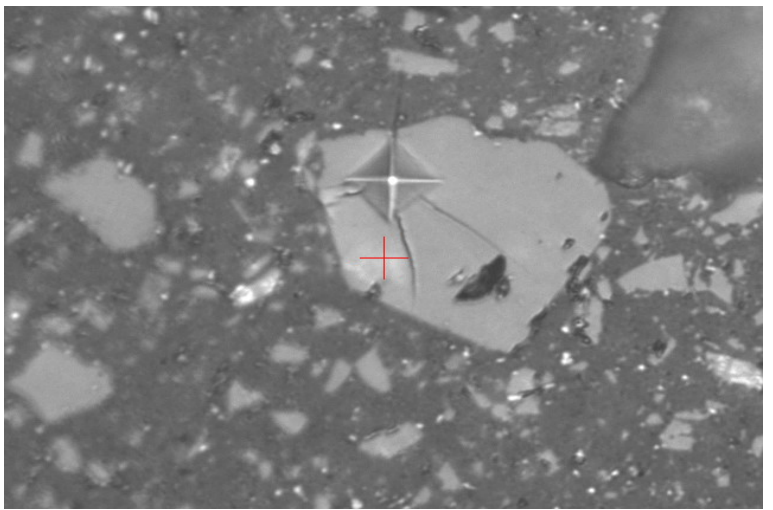

(c)

Figure 5. Morphological pattern of hot-compressed $\left(1620^{\circ} \mathrm{C}\right) \mathrm{Si}-\mathrm{Al}-\mathrm{O}-\mathrm{N}$ composite. Micromechanical indent is made in silicon carbide grain.

Table 1 offers results of tests of SiAlON composite specimens, hot compressed at $1620^{\circ} \mathrm{C}$. Indent was obtained in $\mathrm{SiC}$ grain, they were taken several times and results are given in Table 1, where average hardness is HV: $19.70 \mathrm{GPa}$. Dynamic hardness DH-8.9 GPa, elasticity module E-145 MPa. Table 1 offers results of tests of $\mathrm{SiC}$ grains of the composite microstructure. Indentation was performed in Sic grains at $2 \mathrm{~N}$ loading.

Borders of indents taken from silicon carbide grains are sharp (Figures 5(a)-(c)). Crack that is formed as a result of indenter load on the grain doesn't 
Table 1. Technical characteristics of Si-Al-O-N composite. (a) “Testcondition-SiAlon-200"; (b) “Test result”.

(a)

\begin{tabular}{cccc}
\hline Test mode & Load-unload & & \\
\hline Sample name & SiAlon-zv & Sample No. & Minimum force \\
Test force & $200.000[\mathrm{gf}]$ & Hold time at load & 0.200 [gf] \\
Loading speed & $1.0(7.1448[\mathrm{gf} / \mathrm{sec}])$ & Test count & 21 \\
Hold time at unload & $3[\mathrm{sec}]$ & Parameter & 20 \\
Parameter name & Temp & & \\
Comment & $21.06 .17-$ SiAlon-Zv-200; DHV5-3 & & \\
Poisson's ratio & 0.190 & Indenter type & Vickers \\
Cf-Ap, As Correction & ON & Objective lens & Indenter poisson's ratio \\
Read times & 2 & & 0.070 \\
Indenter elastic & $1.140 \mathrm{e}+006\left[\mathrm{~N} / \mathrm{mm}^{2}\right]$ &
\end{tabular}

(b)

\begin{tabular}{|c|c|c|c|c|c|c|c|c|c|c|}
\hline SEQ & Fmax & hmax & $\mathrm{hp}$ & $\mathrm{hr}$ & DHV-1 & DHV-2 & Eit & Length & $\mathrm{HV}$ & Data name \\
\hline & {$[\mathrm{gf}]$} & [um] & [um] & [um] & & & {$\left[\mathrm{N} / \mathrm{mm}^{2}\right]$} & [um] & & \\
\hline 1 & 200.710 & 4.7107 & 1.9264 & 3.1017 & 442.157 & 2643.803 & $7.211 \mathrm{e}+004$ & 15.792 & 1492.537 & SiAlon-200(2) \\
\hline 2 & 200.786 & 4.2612 & 1.6795 & 2.7414 & 540.546 & 3479.868 & $8.707 e+004$ & 14.621 & 1741.886 & SiAlon-200(4) \\
\hline 3 & 200.800 & 4.9636 & 1.7638 & 3.3296 & 398.419 & 3155.263 & $6.588 \mathrm{e}+004$ & 16.959 & 1294.659 & SiAlon-200(5) \\
\hline 5 & 200.675 & 4.3294 & 2.1587 & 2.9575 & 523.381 & 2105.199 & $9.024 \mathrm{e}+004$ & 15.498 & 1549.415 & SiAlon-200(7) \\
\hline 6 & 200.662 & 3.5295 & 1.5855 & 2.1773 & 787.444 & 3902.198 & $1.254 \mathrm{e}+005$ & 16.595 & 1351.275 & SiAlon-200(8) \\
\hline 7 & 200.661 & 3.6147 & 1.8441 & 2.4494 & 750.723 & 2884.448 & $1.349 \mathrm{e}+005$ & 17.179 & 1260.907 & SiAlon-200(9) \\
\hline 8 & 200.738 & 3.0333 & 1.1085 & 1.7530 & 1066.516 & 7985.353 & $1.660 \mathrm{e}+005$ & 12.866 & 2248.651 & SiAlon-200(10) \\
\hline 10 & 200.866 & 3.0653 & 1.3375 & 2.0446 & 1045.024 & 5488.768 & $1.924 \mathrm{e}+005$ & - & - & SiAlon-200(12) \\
\hline 11 & 200.737 & 3.1154 & 1.3372 & 2.0317 & 1011.028 & 5488.160 & $1.790 \mathrm{e}+005$ & - & - & SiAlon-200(13) \\
\hline 12 & 200.960 & 2.5787 & 1.1425 & 1.5447 & 1477.302 & 7525.888 & $2.536 \mathrm{e}+005$ & 12.135 & 2530.738 & SiAlon-200(14) \\
\hline 13 & 200.923 & 2.7215 & 1.1113 & 1.5055 & 1326.134 & 7952.513 & $2.077 \mathrm{e}+005$ & 11.989 & 2592.358 & SiAlon-200(16) \\
\hline 14 & 200.501 & 2.8549 & 1.0966 & 1.5509 & 1202.544 & 8150.998 & $1.824 \mathrm{e}+005$ & 12.135 & 2524.953 & SiAlon-200(17) \\
\hline 15 & 200.497 & 3.4966 & 1.3136 & 2.2145 & 801.640 & 5679.626 & $1.320 \mathrm{e}+005$ & - & - & SiAlon-200(18) \\
\hline 16 & 200.702 & 2.9626 & 1.1801 & 1.6771 & 1117.798 & 7044.719 & $1.729 \mathrm{e}+005$ & 12.428 & 2409.746 & SiAlon-200(19) \\
\hline 17 & 200.589 & 3.4541 & 1.4444 & 2.0858 & 821.888 & 4700.234 & $1.288 \mathrm{e}+005$ & 14.474 & 1775.634 & SiAlon-200(20) \\
\hline 18 & 201.195 & 3.0666 & 1.0307 & 1.5932 & 1045.886 & 9257.288 & $1.515 \mathrm{e}+005$ & 11.698 & 2726.384 & SiAlon-200(21) \\
\hline Std.Dev. & 0.174 & 0.738 & 0.346 & 0.611 & 324.195 & 2330.548 & 52250.109 & 2.028 & 548.126 & \\
\hline $\mathrm{CV}$ & 0.087 & 21.043 & 23.994 & 27.907 & 36.386 & 42.473 & 36.057 & 14.341 & 27.823 & \\
\hline
\end{tabular}

spread beyond the grain limits. Matrix, due to its high mechanical properties and energy dissipation, subdues crack spreading and composite hardness retains 
its value. Such large grains are few and speaking about mechanical properties of the material according to such grains should not be relevant, since increase of their dispersion rate is not a problem, while it gives interesting picture for the purposes of investigation. Especially interesting is Figure 5(b). In this case a crack on the right side of the indent develops so intensely and by such high energy, that the crack spreads up to the matrix, attacks energetically the matrix, returns back, transects diagonally the grain and collides again with the matrix from the other side of the grain, but fails to destruct it. It should be stated that the crack retains high energy and develops diagonally on the other side of $\mathrm{SiC}$ grain, and losing energy it fails to reach matrix. The crack that is developed from the lower edge reaches matrix, but energy dissipation in the grain and critical coefficient of matrix stress intensity-Kic are so high that the crack disappears at the matrix. Figure 5(a) and Figure 5(b) shows vividly directions of crack propagation. As is known, in this case too Kic has great significance for material crack-resistance, since after detachment, the flaw develops approximatively by $2000 \mathrm{~m} / \mathrm{sec}$ speed and at this moment, material resistance is defined not only by the speed of shock on the crack matrix but also by Kic value of the material.

Dynamic hardness (DH) is determined according to the indenter load value and the depth of its indentation in the material in the process of testing and its value is computed by the formula $\mathrm{DH}=a \times F / h^{2}$; where $a$-is a constant value and depends on indenter form; for Vicker's indenter $a=3.8584$. Advantage of the method compared to measuring of common static, that is, linear dimensions of indents (diagonal) is that it covers plastic, as well as elastic components. Results of measuring don't depend on indent sizes, loads and non-homogeneity of elastic recovery.

Dynamic hardness was determined in load-unload regime before elastic relaxation took place. For each concrete load seven readings were taken, two marginal values were discarded and remaining five values were averaged. Relevant micro-hardness values were determined automatically. Hold-time at maximum loading equaled to $5 \mathrm{sec}$, at the end of unloading-3 sec. (Figure 5).

Indentation was performed in sample matrix, which consisted of B-SiAlON. As a result of testing its average dynamic hardness equaled to, $\mathrm{DHV}=8.9 \mathrm{GPa}$ this is a rather high value.

From load-unload dependence graph (Figure 6) we determined elasticity module value by determination of rigidity $S=(\mathrm{d} F / \mathrm{d} h) h-h_{\max }$. It is a tangent of load-unload graph at the initial point of unloading. A device determines elasticity module of tested material, and its average value in case of our sample equals: $\mathrm{E}=145 \mathrm{GPa}$ (Table 1). Patterns of indents conform well to graphical data given in Figure 6. Depths of all imprints differ from each other and they vary from 2.5 to $5 \mu \mathrm{M}$. Probably for this material $2 \mathrm{~N}$ load is somewhat big than optimal load. Figure 5 confirms it. Silicon grain acquired such high energy from diamond pyramid that the crack managed to transect the whole width of the grain several times, because the crack received high energy and detachment was 


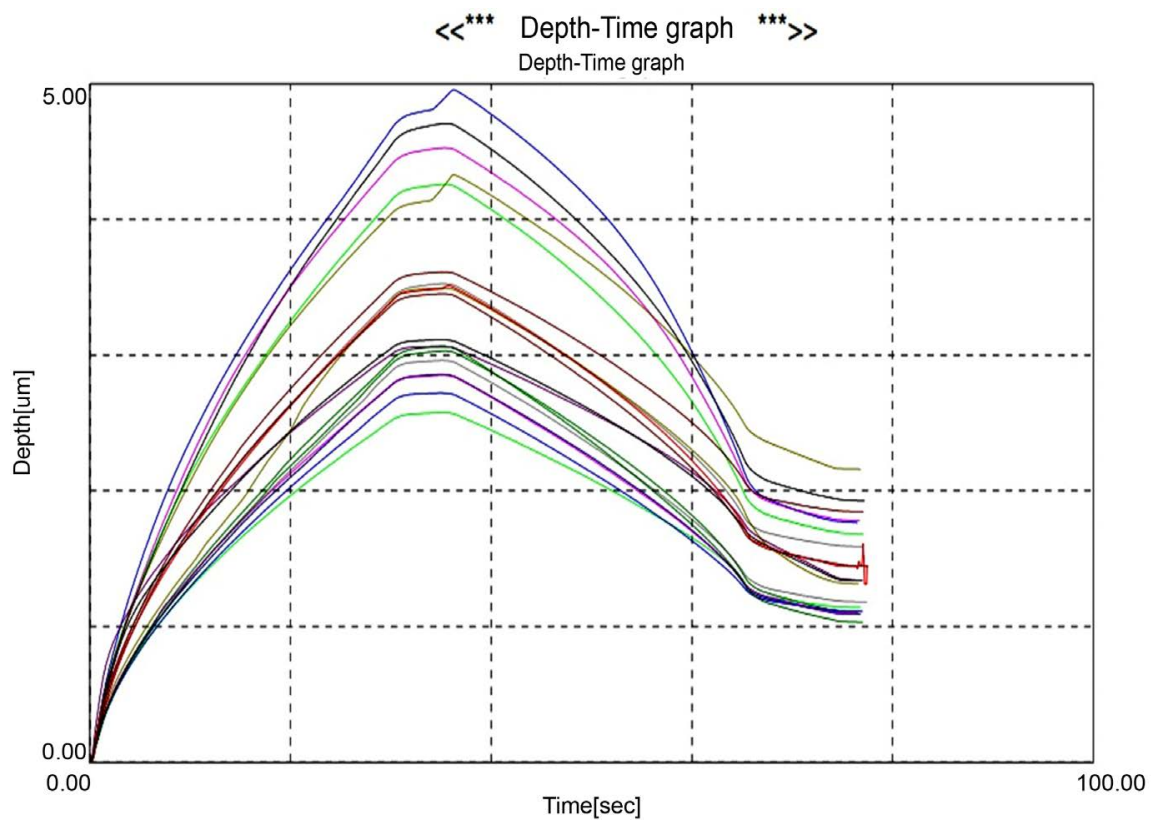

(a)

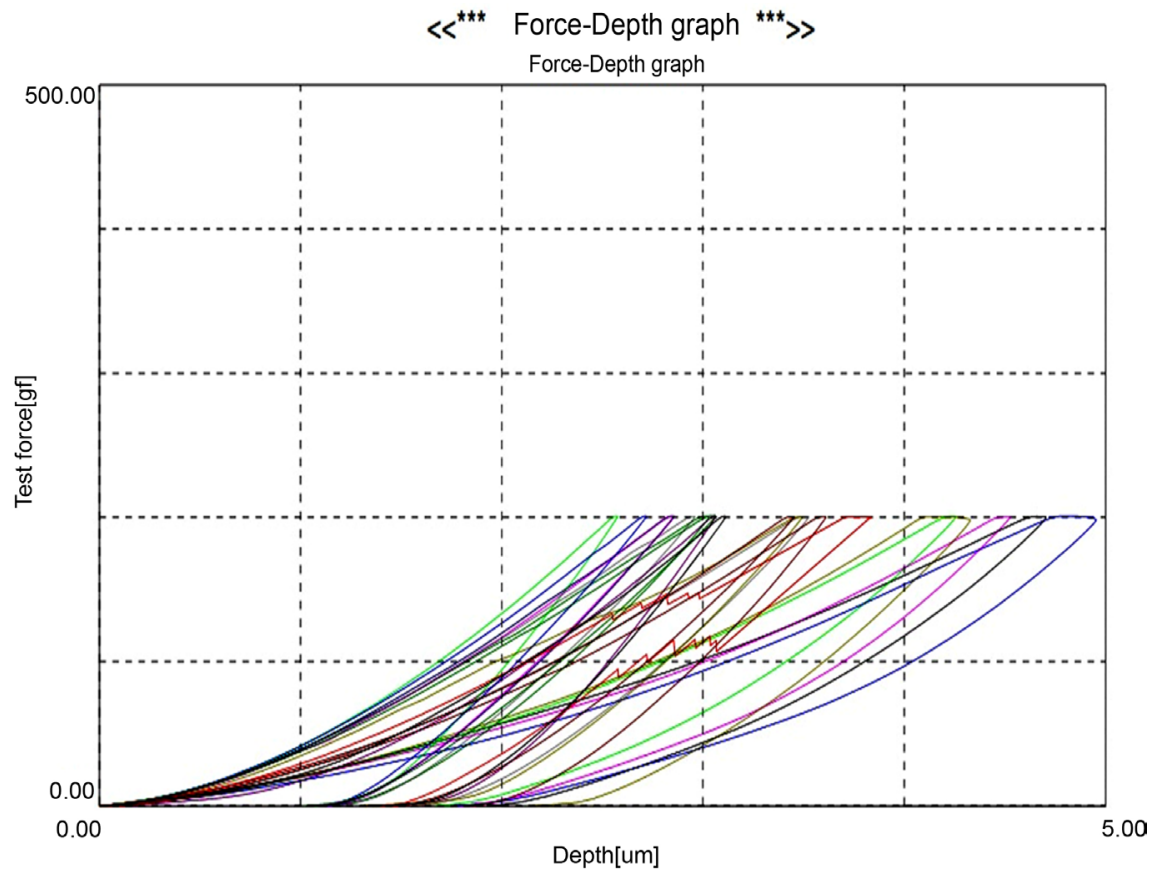

(b)

Figure 6. Micro-mechanical properties of Si-Al-O-N composite at $2 \mathrm{~N}$ loading: (a) indenter depth-time dependence; (b) indenter force-depth graph.

realized from the crack top by the energy that exceeded critical stress intensity. The same was proved at the application of test force (200 $\mathrm{g}$ approximately equals to $2 \mathrm{~N}$ ) at taking indent depth (Figure 6(b)). In this case too indent depths for 18 tests are different and they vary from 2.5 to $5 \mu \mathrm{M}$.

Thermo-structural stresses in the process of changes of temperature fields can be induced: by thermal expansion anisotropy of even only one phase, by aniso- 
tropy of dilatation of non-cubic crystalline lattice of materials, by difference in thermal linear expansion of adjacent phases in heterogeneous system, phase transformations, which are accompanied by specific volumetric changes of phases. Methods of quantitative evaluation of resistance to thermal shocks provide mainly determination of resistances to the first order thermo-elastic stresses, which are formed in elastic bodies and in which there are no plastic deformations and phase transformations [20]. If stresses are lower than material hardness, a body will be stable to thermo-shocks [12] and the resistance of such bodies to thermal shocks can be evaluated by the ratio of hardness limit to maximum thermal stress:

$$
R=\delta a / a^{\prime} \mathrm{E}
$$

where $R$-is the factor of resistance to thermal shocks, $\delta$-is mechanical strength of the material at bending, a-is thermal coefficient of linear expansion, E-Young's module, $a^{\prime}-\lambda / y C$-material's temperature conductivity, $\lambda$ sd-heat conductivity, $y$-density, $C$-specific heat capacity.

The formula doesn't consider sample form, size and dependence of resistance to thermal shock. For real evaluation it is necessary to consider impact of body dimensions.

$$
R=\delta /(\operatorname{Ea} \beta(\mathrm{Tk}-\mathrm{To}))
$$

where Tk and To-are final and starting temperatures of a body, $\beta=r_{m} h / \lambda$ and $\beta=\delta h / 2 \lambda$ - the sphere and infinite plate, $h$-heat transmission coefficient between the body surface and environment. According to Kingery's opinion, physical properties of material don't suffer changes at alteration of temperature in $\Delta \mathrm{T}_{\text {destr }}$. Interval and he recommends the following definition for thermal-shock factor:

$$
R^{\prime}=2 \delta_{\text {destr }} \cdot(1-\mu) / \mathrm{Ea}=\Delta \mathrm{T}_{\text {destr }} / B
$$

where $B$ factor depends on body geometry, $\delta_{\text {destr }}$ - -depends on mechanical strength of the material at stretching and $\mu$-Poisson coefficient.

Kingery, Buessem and others [21] [22] [23] recommend that at various conditions of thermal loading, at the evaluation of material resistance to thermal shocks it is necessary to use various criteria. They offer the below given criterion for the study of heat transition conditions, in the process of cooling by water:

$$
R=\delta_{\text {bend }}(1-\mu) / 3 \mathrm{Ea}
$$

when relaxation periods significantly exceed possible service period of work-pieces, no significant thermal stresses occur and selection of materials is based on their elasticity properties, that is on the criteria [12]

$$
R^{\prime}=\delta(1-\mu) / \mathrm{Ea} R^{\prime \prime}=R^{\prime} \lambda R^{\prime \prime \prime}=\mathrm{E} / \delta^{2}(1-\mu)
$$

where $R^{\prime}$-is the criterion, which defines material resistance to the formation of cracks in the process of thermal shocks, $R^{\prime \prime}$-is the criterion, which evaluates ability of the material to resist thermal loads, at small values of heat-exchange 
coefficient; $R^{\prime \prime \prime}$-is the criterion, which defines material resistance to propagation of already formed cracks.

The offered data enable us to conclude that high mechanical strength and heat conduction together with low elasticity properties and thermal expansion provide high resistance of materials to crack formation and such ceramics can work at high temperature gradients and at high temperatures.

For electro-technical products synthesized by us we used Harcourt's method [2] of cycle loading. Cyclic heating was started at $140^{\circ} \mathrm{C}$, at $20 \mathrm{~min}$ hold-time at the end temperature; then it was kept on water bath at $17^{\circ} \mathrm{C}$ for 10 minute. The cycle was repeated every $20 \mathrm{~min}$. Plate sizes were $50 \times 50 \times 8 \mathrm{~mm}$. Results are given in Table 2.

Analysis of the table shows that barium-containing electroceramic synthesized on the base of barite and geopolymers enables us to conclude that celsianceramic B1, with $93 \%$ celsian phase, sintered at various temperatures, in definite regimes, with zero open porosity, is resistant and stable than B3. B1 is characterized by high value of thermal resistance $-480^{\circ} \mathrm{C}$. Apparently it is associated with the low coefficient of dilate, which conditions high resistance of work-pieces to thermal shock and correspondingly resistance to stress distribution. In this material concentration of barium and aluminum silicates is low and it amounts to only some percents and their negative impact on resistance to thermal shocks is insignificant. Apparently lower rate of resistance to thermal shocks that is shown by $\mathrm{B} 3$ ceramic is conditioned by its multiphase composition: celsian $\mathrm{BaO} \cdot \mathrm{Al}_{2} \mathrm{Os} \cdot 2 \mathrm{SiO}_{2}$, mulite $-3 \mathrm{Al}_{2} \mathrm{O}_{3} \cdot 2 \mathrm{SiO}_{2}$, corundum $-\mathrm{Al}_{2} \mathrm{O}_{3}$ and vitreous phase, which is more in B1.

Various expansion coefficients of the above referred phases factually exert negative impact on thermal resistance of the material (Table 2). Material structure, its anisotropy and homogeneity determine mostly the rate of thermal resistance. Significant criterion of the resistance to thermal shock of the materials is the presence or absence of closed pores at zero open porosity in consolidated work-piece. They are apt to create thermal flaws in the material on the heated surface. Closed porosity at $1400^{\circ} \mathrm{C}$, is somewhat higher at $1450^{\circ} \mathrm{C}$ and $1500^{\circ} \mathrm{C}$ (Table 2), which is reflected on the criterion R'. Lower thermal resistance of B3 compared to that of $\mathrm{B} 1$, proves indirectly crack formation at the borders of

Table 2. Resistance to thermal shocks of barium containing ceramics.

\begin{tabular}{cccccccccccc}
\hline $\begin{array}{c}\text { Index of materials, } \\
\text { and burn } \\
\text { temperature, } \mathrm{T}{ }^{\circ} \mathrm{C}\end{array}$ & $\begin{array}{c}\text { Open } \\
\text { porosity, \% }\end{array}$ & $\begin{array}{c}\text { True } \\
\text { porosity, } \%\end{array}$ & $\begin{array}{c}\text { Compactness } \\
\rho \mathrm{g} / \mathrm{sm}^{3}\end{array}$ & $\sigma, \mathrm{MPa}$. & $\begin{array}{c}\mathrm{A}, 10^{-6} \\
{ }^{\circ} \mathrm{C}^{-1} \\
20-900\end{array}$ & $\mathrm{E}, \mathrm{GPa}$. & $\mu$ & $R^{\prime}$ & $\begin{array}{c}\tau \\
R^{\prime \prime} \\
\mathrm{BT} / \mu\end{array}$ & $\begin{array}{c}R^{\prime \prime \prime} \\
10^{-4} \\
\mathrm{M}^{2} / \mathrm{kg}\end{array}$ \\
\hline $\mathrm{B}^{1} 1410$ & 0 & 14.2 & 2.99 & 66.4 & 4.1 & 71.32 & 0.283 & 163 & 210.3 & 225.6 \\
$\mathrm{~B}^{1} 1450$ & 0 & 7.8 & 3.03 & 78.7 & 4.1 & 74.59 & 0.212 & 161 & 164.3 & 220.0 \\
$\mathrm{~B}^{1} 1500$ & 0.1 & 9.8 & 2.96 & 59.3 & 4.1 & 72.20 & 0.280 & 144 & 185.8 & 285.2 \\
$\mathrm{~B}^{3} 1410$ & 0.0 & - & 2.60 & $78 \tau .6$ & 4.1 & 69.35 & 0.233 & 220 & 420.2 & 172.9 \\
$\mathrm{~B}^{3} 1450$ & 0.0 & - & 2.52 & 56.0 & 4.1 & 79.22 & 0.258 & 128 & 244.4 & 340.0 \\
\hline
\end{tabular}


different phases [20]. In the ceramic B1, which is mainly mono-phase one, from $1400^{\circ} \mathrm{C}$, up to $1500^{\circ} \mathrm{C}$ and when open porosity is zero, elasticity module and Poisson coefficient suffer insignificant changes (Table 2). Mechanics at plasticity and thermal conductivity of the material sintered at $1500^{\circ} \mathrm{C}$ suffer definite decrease which is reflected in R' criterion, which is determining for material evaluation, at the conditions of its exploitation when we pursue to avoid crack formation. It appears that growth of sizes of the closed pores makes impact on these processes. Relatively higher stability of the given properties of the material B1 enables us to think that B1 can be used in the conditions when creation of the cracks which don't affect negatively the integrity of the piece, don't hinder its using [12]. For evaluation of quality of this material we offer the criterion, the value of which at various temperatures is stable than that of B3 (Table 2). The reason of this, according to our opinion is poly phase state of the latter, B1. Generally, high values of the criterion for both materials refer to the fact that at thermal loading they accumulate less energy, which determines lower rate of their decomposition. It should be stated that analysis of ceramic properties is very difficult, because rupture occurs not only thanks to one mechanism, but because of some absolutely different phenomena at various conditions. The situation is complicated by the fact that one and the same material suffers decomposition differently, depending on stress value, load velocity, prehistory of specimens, environment conditions and temperature. Disregard of any factor will lead us to the significant error. Figure 7 offers curves of material decomposition at various loads.

According to the above stated, while discussing the properties of ceramic materials and composites, integration of rupture stress issues is a very hard problem because of coincidence of complex processes in materials. This is why we considered proper to offer the characteristic of rupture stress which will comprise all

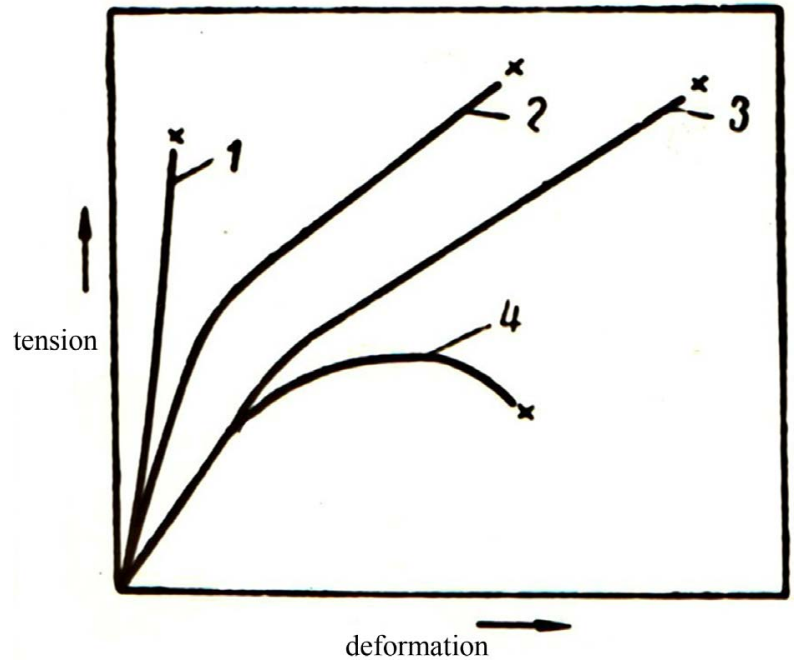

Figure 7. Brittle and plastic decomposition; (1) Brittle decomposition; (2) Plastic decomposition, test at twisting; (3) The same test for stretching; (4) Nominal hardness at rupture. 
those conditions and properties which will take place in the process at critical loading of the work-piece and the rupture will be inevitable. It can occur in the cases of external energy charge on the work-piece and as a result, accumulation of energy in the piece, because of thermo-structural changes and external mechanical stress distribution. The formula of decomposition stress energy offered by us is:

$$
\mathrm{E}_{\mathrm{td}}=\mathrm{m} * \mathrm{a}_{\mathrm{c} . \mathrm{p}} \text {. }
$$

where $\mathrm{E}_{\mathrm{td}}$-is energy decomposition tension; m-mass; a-speed of crack propagation.

Decomposition stress energy ${ }^{1} E_{t d}$ equals to the product of $m$-mass and crack propagation speed- $\mathrm{a}_{\text {c.p }}$.

In our case a sample of electro-technical material had a form of a rod, and it had the following sizes:

Length $\mathrm{l}=110 \mathrm{~mm}$; width $b-20 \mathrm{~mm}$; height $a=10 \mathrm{~mm}$. Mass of a rod of such sizes that was sintered at $1450^{\circ} \mathrm{C}$-equaled to $45.5 \mathrm{~g}$. The work-piece was fully consolidated by zero open pores. If we admit that in the process of decomposition velocity of crack propagation by its dependence on stress intensity factor (from critical state) on the v-k curve is in the third section (Figure 4), where its propagation takes place by detachment from the top and velocity equals to approximately $2000 \mathrm{~m} / \mathrm{sec}$, according to our formula decomposition stress energy will be:

$$
\mathrm{E}_{\mathrm{td}}=45.5 \times 2000=91 \mathrm{kj}
$$

Thus, if we define universal connection between total energy of the work-piece and its mass, we'll receive formula of rupture stress energy offered by us.

\section{Conclusions}

The formula [24] offered by us describes transformations of impact of energies developed as a result of external mechanical stresses and thermal and air-thermal shocks on the work-piece into internal energies in the work-piece. These affect the defects existing in the material and it, in the first place, makes impact on crack propagation. On the crack top, while developing critical Intensities, there occurs pluck from the crack top.

Correlative relation of transformation of external stresses of energies into inner energies of the material was determined which determines propagation of defects existing in the work-piece at high energies exceeding the critical, when stress intensity factor overcomes crack resistance and rupture stress energy develops. Thus, universal relation between total energy developed in the work-piece and work-piece mass is established with respect to external energy of rupture stress.

\footnotetext{
${ }^{1}$ Energy (from Greek energies-action) of the common measure unit for various forms of material movements, which is considered in physics. Various types of energies are used for quantitative characterization of qualitatively different forms of motion and for relevant interactions, such as: mechanical, internal, gravitational, electro-magnetic, and nuclear and others. In international system of units-SI energy is expressed in Joules.
} 


\section{Acknowledgements}

I am grateful to Ilia Vekua Institute of Applied Mathematics of IvaneJavakhishvili Tbilisi State University for assistance in the research of Structural and Micro Mechanical Characteristics.

\section{Conflicts of Interest}

The author declares no conflicts of interest regarding the publication of this paper.

\section{References}

[1] Lawn, B. (1999) Fracture of Brittle Solids. Cambridge University Press, Cambridge.

[2] Kovziridze, Z., Hennicke, H.W. and Kharitonov, F. (1998) Thermomechanics of Ceramics. Fachhochschule Karlsruhe HochschulefuerTechnik, Karlsruhe.

[3] Kovziridze, Z., Aneli, J., Nijaradze, N. and Tabatadze, G. (2017) Ceramic and Polymer Composites. LAP LAMBERT Academic Publishing. International BookMarket Service Ltd.

[4] Kovziridze, Z., Nijaradze, N., Tabatadze, G. and Aneli, J. (2016) Ceramic and Polymer Composites. Monograph, Georgian Technical University, Tbilisi.

[5] Budworth, D.W. (1970) Theory of Pore Closure during Sintering. Transactions of the British Ceramic Society, 69, 29-31.

[6] Grifith, A.A. (1920) The Phenomena of Rupture and Flow in Solids. Philosophical Transactions of the Royal Society A, 221, 163-198.

[7] Shvedkov, E.L., Kovensky, I.I., Denisenko, E.T. and Zyrin, A.V. (1991) Dictionary Reference Book for New Ceramic. Academy of Sciences of Ukraine. Institute of Problems of Material Sciences, Kiev, "NaukovaDumka”, 115-116.

[8] Richerson, D.W. (1992) Modern Ceramic Engineering. Marcel Dekker Inc., New York.

[9] Grathwohl, G. and Kuntz, M. (2004) Mechanische Eigenschaftenim Buch Technische Keramik. Herausgeber W. Kollenberg, VULKAN_VERLAG ESSEN, Germany, 45-55.

[10] Munz, D. and Fett, T. (1999) Ceramics: Mechanical Properties, Failure Behavior, Materials Selection. Springer-Verlag Berlin Heidelberg, New York, 61. https://doi.org/10.1007/978-3-642-58407-7

[11] Grathwohl, G. (1993) Mechanische Eigenschaftenkeramischer Konstruktionswerkstoffe DGM Informationsgesellschaft mbh.

[12] Natsenko, A.I. (1971) Thermal Stability of Brittlematerials. Journal of Metallurgy, $15,189-208$

[13] Kingery, W.D. (1963) Measurements at High Temperatures. "Metallurgizdat", Moscow, 466.

[14] Sobolev, I.D. and Egorov, V.I. (1962) Thermal Fatigue and Thermal Shock. In: Stability and Deformation in Uneven Temperature Fields, "Gosatomizdat", Moscow, 194.

[15] Troshchenko, V.T. (1971) Fatigue and Inelasticity of Metals. "NaukovaDumka", Kiev, 268.

[16] Pisarenko, G.S., Troshchenko, V.T., Timoshchenko, V.G., et al. (1962) Stability of Metal-Ceramic Materials and Alloys at Normal and High Temperatures. Kiev. Pub- 
lished by Academy of Sciences of Ukraine, SSR, 275.

[17] Geitwud, B.E. (1959) Temperature Stresses. Moscow Edition, "Foreign Literature", 349.

[18] Kovziridze, Z., Nijaradze, N., Tabatadze, G., Cheishvili, T., Mestvitishvili, Z., Mshvildadze, M. and Darakhvelidze, N. (2017) Obtaining of Composites by Metal-Thermal and Nitriding Processes in Si-Sic-Al-Geopolymer System. Ceramic and Advanced Technologies, 19, 33-52. http://www.ceramics.gtu.ge https://doi.org/10.4236/jectc.2017.74009

[19] Kovziridze, Z., Nijaradze, N., Tabatadze, G., Cheishvili, T., Mshvildadze, M., Mestvirishvili, Z., Kinkladze, V. and Daraxvelidze, N. (2007) Obtaining of SiAlON Composite via Metal-Thermal and Nitrogen Processes in the SiC-Si-Al-Geopolymer System. Journal of Electronics Cooling and Thermal Control, 7, 103-122. http://www.scirp.org/journal/jectc

[20] Maslennikova, G.N. and Kharitonov, F.Ya. (1977) Electro-Ceramic, Stable to Thermal Shocks. Moscow. Energy, 9-10.11-18, 163-175.

[21] Kingery, W.D. (1955) Factors Affecting Thermal Shock Resistance of Ceramic Materials. Journal of the American Ceramic Society, 38, 3-15. https://doi.org/10.1111/j.1151-2916.1955.tb14545.x

[22] Buessem, W. (1955) Thermal Shock Testing. Journal of the American Ceramic Society, 38, 15-17. https://doi.org/10.1111/j.1151-2916.1955.tb14546.x

[23] Davidge, R. and Tappin, G. (1967) Thermal Shock and Fracture in Ceramics. Transactions of the British Ceramic Society, 66, 405-422.

[24] Failure Stress Energy Formula. Georgian National Intellectual Property Center “Georgia Patent" (Sakpatenti). Certificate of Deposition 7289.2018.03.27. 